\title{
Problem of Exclusive Breastfeeding Practices Among Teenage Rural Mothers in Selected Agrarian Community in Southwest Nigeria
}

\author{
Ogunwemimo, Funmilayo. Omolola ${ }^{1^{*}} \quad$ James, Sarah. Adewunmi $^{1} \quad$ Adeoye, Adekunle. Stephen ${ }^{2 *}$ \\ 1.Department of Home Economics. Federal College of Education, Abeokuta, Ogun State. Nigeria P.M.B. 2016. \\ Abeokuta. Ogun State, Nigeria \\ 2.Department of Agricultural Extension and Rural Development, Federal University of Agriculture, Abeokuta.
} (FUNAAB) P.M.B 2240. Abeokuta. Ogun State, Nigeria

\begin{abstract}
The practice of exclusive breastfeeding among teenage rural mothers is still low despite the associated benefits. This study investigates exclusive breastfeeding practices among teenage rural mothers selected agrarian communities in Southwest Nigeria. Using a concurrent mixed-method approach, a structured questionnaire was administered to 415 breastfeeding mothers. In-depth interviews were also held with breastfeeding mothers (11), nurses (10), and a focus group discussion session with grandmothers. The result reveals that $59.1 \%$ and $61.0 \%$ of the respondents were between the age range of 17 - 19 with the mean age of 19years and the majority $(81.4 \%$ and 93.0) were Yoruba in Ogun and Oyo State respectively. The result showed that respondents in both Ogun and Oyo State receive information about exclusive breastfeeding (51.6\% and $62.0 \%)$ and thus practice it $(51.6 \%$ and $55.5 \%)$. The result showed a moderate level of awareness of breastfeeding $(60.9 \%$ and $62.0 \%)$ among the teenage rural mothers was recorded and above half $(51.6 \%$ and $55.5 \%)$ of the teenage rural mothers reveals that they practice exclusive breastfeeding, the majority $(62.2 \%)$ of the respondents in Oyo State and almost half $(46.9 \%)$ of the respondents in Ogun State practiced exclusive breastfeeding for over 8 weeks. Some of the factors influencing the adoption of exclusive breastfeeding were personal determination/experience, encouragement from their mothers, and nurse and midwife advice in the two states sampled. Problems encountered by teenage mothers in the practice of exclusive breastfeeding were maternal health problems, the baby continues to be hungry, fear of addicted to breast milk alone, pains in the breast. T-test result shows that there is a significant difference $(t=93.732)$ in the problems encountered by teenage rural mothers in the practice of exclusive breastfeeding in the study area. It was concluded that compliance to Exclusive Breastfeeding for six months was still minima in Ogun and Oyo State and still face multiple problems. The study, therefore, recommended that there is an urgent need for policies that will aim at providing acceptable food supplements that could aid the supply of breast milk among postpartum teenage rural mothers, especially those with low socioeconomic status.
\end{abstract}

Keywords: Problems; Breastfeeding practices; Exclusive breastfeeding; teenage mothers; Yoruba people.

DOI: $10.7176 / \mathrm{JHMN} / 80-11$

Publication date:September $30^{\text {th }} 2020$

\section{Introduction}

The need to protect, promote and support breastfeeding practices in our communities has been widely recognized by many in both rural and urban areas of our country Nigeria. It is in an understanding of this noble objective that the Federal Ministry of Health and Social Services in conjunction with UNICEF and the World Health Organisation (WHO) launched the Baby-Friendly Hospital Initiative (BFHI) to protect, promote and support exclusive breastfeeding practices in Nigeria. Exclusive Breastfeeding, (EBF) which giving breast milk only and no other liquids, except drops or syrups with vitamins, mineral supplements, or medicines, is superior to nonexclusive breastfeeding with a protective effect against both morbidity and mortality (Kramer and Kakuma 2004, León-Cava, et al., 2002). Exclusive breastfeeding provides low cost, complete nutrition for the infant, protects the child against a series of infections which including infant diarrhea, and prolongs lactation amenorrhea, etc. WHO recommends exclusive breastfeeding (EBF) up to six months of age (WHO, 2007, 2009)? During these six months, no liquid, semisolid or solid food or breastfeeding substitute should be given to the infants except for medicine and/or oral rehydration solution. According to Kramer (2010) ascertained that EBF has been considered to be beneficial to the health and wellbeing of infants and mothers. A child who is EBF for six months is more likely to be protected against series of infections such as respiratory illness, atopic eczema, risk of allergy, asthma, and type II diabetes ((Ip, et al., 2009; Malla, et al., 2011). About 24\% of children less than 5 years was reported to be moderately or severely underweight in sub-Saharan Africa, according to UNICEF in West Africa, the proportion of underweight children under five years of age was $24 \%$, as reported in the State of the World's Children 2009. According to UNICEF, only $15.1 \%$ of babies less than 6months of age were exclusively breastfeed, between 2008 and 2012 in Nigeria [UNICEF, 2013). The Nigeria Demographic and 
Health Survey 2013 however reported a slightly higher prevalence (17\%) for exclusive breastfeeding even though the average duration of the practice across the country was about 15days (NPC/ICF, 2013). Several factors have been associated with breastfeeding practices of women in developing countries including maternal age, educational status, wealth quantile, and place of delivery (Joshi, et al., 2014). According to the Nigerian Demographic and Health Survey (NDHS), in 2008 17\% of children were exclusively breastfed for less than 4 months, while 13\% were exclusively breastfed for less than 6 months. The median exclusive breastfeeding period in Southwest Nigeria by months in the year 2003 was 7 months. In the year 2008, it was for 6 months. Within the same period, early initiation of breastfeeding among women in the region was 12.7\% in 2003 but increased to $35.5 \%$ in the year 2008 (NPC/ICF, 2009). All these figures are far below the $90 \%$ level recommended by the WHO (Jones et al.,2003). Nigeria has the highest under-five rural mortality rate of 242.7 per 1,000 among selected sub-Saharan Africa countries (Anyamele, 2009). Successful breastfeeding is crucial to the curbing of infant malnutrition and achieving the millennium development goals four (reducing child mortality) and five (improving maternal health) (WHO, 2005).

Based on available evidence, achievements of both goals are still far from the desired progress (WHO, 2010). Breastfeeding practices, including initiation and duration, are influenced by multiple interwoven factors which include health, psychosocial, cultural, political, and economic factors (Cripe, 2008). Among these factors, decisions regarding initiation and duration of breastfeeding in low-income countries are influenced by education, employment, place of delivery, family pressure, and cultural values (Otoo, et al., 2009; Ogunlesi, 2010; and Henry et al., 2010). Maternal characteristics such as age, income, education, knowledge, and ethnicity have been associated with the initiation and continuation of EBF (Wiener and Wiener, 2011). The lack of support, encouragement, and education from healthcare professionals, family, and friends can become barriers to exclusive breastfeeding (Moore and Coty, 2006; Murimi, et al., 2010). In Nigeria, while breastfeeding initiation is on the increase, the duration, and practice of exclusive breastfeeding among women who had their delivery in a health facility, and outside such facility, has remained low (Ogunlesi, 2010). The early introduction of complementary feeding, based on erroneous assumptions, affects breastfeeding initiation and sustainability (WHO, 2005). Among the Yoruba people, a common belief around infant feeding is that exclusive breastfeeding is beneficial to both infants and mothers, but complementary feeding is essential for babies to adapt to other meals with ease (Ojofeitimi, et al., 2000, Lawoyin, et al., 2001 and Tella, et al., 2008). While the relevance of colostrum had increased among the breastfeeding mothers in this sampled area, traditional child feeding practices such as feeding infants with herbal concoction are still common among Yoruba people. This may be hinged on some cultural beliefs associated with childbirth and rearing practices among the Yoruba people in Southwest Nigeria (Ajibade, 2004, and Salami, 2008). Breastfeeding culture is well enshrined in the various ethnic groups in Nigeria (Gartner, 2005), but the low practice of exclusive breastfeeding persists. The Nigerian Demographic Health Survey in Nigeria, 2008 showed that only 13\% of children below six months are exclusively breastfed while $87 \%$ of Nigerian infants below six months receive complimentary liquids or foods. Only $19 \%$ of the breastfeeding mothers whose infants were below or up to six months of age in this study practiced exclusive breastfeeding. Breast milk contains antibodies and essential nutrients, necessary for the promotion of health and adequate development of infants and very young children. Evidence-based research articles reported that the most common factors for discontinuation of early breastfeeding were lack of paid maternal leave, maternal beliefs, and perceptions, such as insufficient breast milk and painful breastfeeding associated with incorrect infant position and latch ( $\mathrm{Li}$, et al., 2008; Ogbuanu, et al., 2011). Several factors have been linked with breastfeeding practices of women in developing countries including maternal age, educational status, wealth quantile, and place of delivery (Joshi, et al., 2014, Nyanga, et al., 2012, Ukegbu, et al., 2011). Globally, no more than $40 \%$ of infants below six months of age are exclusively breastfed (WHO, 2014). Identifying the barriers to exclusive breastfeeding will help to develop appropriate clinical practice guidelines to overcome those hindrances associated with discontinuation of exclusive breastfeeding practices among both rural and urban mothers in Sub-Sahara Africa and during the early postpartum period. One of the key strategies in promoting breastfeeding to childbearing women is antenatal breastfeeding education (Jennifer, et al., 2013). Hence, this study adopts a mixed-method design in exploring nursing mothers' breastfeeding practices, beliefs, experiences, and constraints to exclusive breastfeeding. The experiences and views of breastfeeding mothers were complemented with that of grandmothers and nurses. Grandmothers are an important source of support for new mothers. Based on their roles, their infant feeding experience and knowledge can influence mothers' decisions to initiate and continue breastfeeding (Grassley and Eschiti, 2008). It is, therefore, against this background that this study looks at the objectives of the study: (i.) Socio-economic characteristics of the teenage rural mothers' in the study area. (ii). Evaluate the infant feeding pattern among teenage mothers in the study area. (iii). identify factors that can influence the adoption of exclusive breastfeeding practices in the study area. (iv). identify the problems encountered by teenage mothers in the practice of exclusive breastfeeding in the study area. 


\section{Methodology}

\section{Research design and study setting}

A complimentary mixed method design was used for this study which consists of a structured questionnaire, indepth interviews, and focuses group discussion. The study population consisted of teenage rural breastfeeding mothers, nurses, and grandmother. The inclusion criteria for the breastfeeding mothers include ethnic affiliation (Yoruba extraction), having a living child whose age was between three months and one year; and currently seeking postnatal care at the urban comprehensive health center. Nurses attached to the pediatrics unit of the health facility were invited for the interviews. Grandmothers that are of the Yoruba extraction who is currently providing informal nursing care within the last one and half years were recruited. In the quantitative phase of this study, the structured questionnaire was the leading method; while face-to-face in-depth interviews and focus group discussion were adopted in the qualitative phase of the study to enhance, as well as to clarify, and support the quantitative results generated in the survey (Cameron, 2009). The survey among breastfeeding mothers and the in-depth interviews with nurses were carried out between February and May 2017 at Local Government Primary Health Centre (PHC) in Ogun and Oyo State, Southwest Nigeria. Some of the nurses at the health facility had been trained in exclusive breastfeeding through the Baby-Friendly Hospital Initiative (BFHI) sponsored by the United Nations Children's Fund (UNICEF). The focus group discussion was also conducted in July 2017 at a preferred location suggested by the grandmothers in Ogun and Oyo State, Nigeria. The study location is a rural settlement in Ogun and Oyo State, Southwest Nigeria. The total population of the area is 27,581,992 with Lagos state having 9,013,534; Oyo 5,591.598; Ondo 3,441,024; Osun 3,423, 535; Ogun 3,728,098 and Ekiti having 2,384212; (National Population Census 2006). The study will be viewed from the geo-political zones. Agriculture forms the base of the overall development thrusts of the zone, with crop farming as the main occupation of the people in the area. Despite the availability of modern health care facilities, sociocultural and economic factors of the rural dwellers have sustained the relevance of traditional birth attendants and private hospitals in the provision of primary care services to many Nigerian rural communities.

\section{Sampling procedure}

Respondents in the quantitative component were recruited using a convenience sampling technique. All the teenage rural breastfeeding mothers presented at each Local Government Primary Health Centre in Ogun and Oyo State for scheduled clinic visits from February 2017 to June 2017 were invited to participate in the study. Of this population, 415 breastfeeding mothers who met the study inclusion criteria agreed to participate in the two States (200 in Ogun and 215 in Oyo). Ten nurses at the Primary Health Centre facility assisted with the recruitment of potential respondents. We focused on the breastfeeding experiences and practices of mothers seeking care at a PHC facility, although there are variations in breastfeeding initiation and practices in the wider population of breastfeeding mothers. Of the 455 nursing mothers who met the inclusion criteria, only 415 volunteers responded to the interviewer-administered questionnaire. Forty breastfeeding mothers declined participation across the two-study area because they felt they had already taken too much of their time at the health facility, have urgent issues to attend to, or because they do not want to share their thought with us. Hence, the analysis was based on 415 valid responses, representing a response rate of $91.2 \%$. In the qualitative strand, a purposive sampling approach was adopted in recruiting 10 nurses each in the two States in the pediatrics unit of the health facility. 15 grandmothers that met the study inclusion criteria were recruited for the focus group discussion.

\section{Instruments}

Three research instruments consisting of a questionnaire, in-depth interview, and a focus group discussion guide were adopted to explore the socio-economic characteristics, the breastfeeding beliefs, practices, and problem of teenage rural nursing mothers on exclusive breastfeeding practices in the study area. Three pediatricians and a community health expert were asked to assess the content validity of the questionnaire. Before the main study, a pre-test of the instrument was undertaken among 30 nursing mothers recruited outside the study location. This was to check whether the questionnaire was understandable and realistic. The questionnaire included three sections. The first comprised questions that elicit respondent's economic characteristics i.e. age, level of education, place of childbirth, occupation, marital status, sex of the baby, household size, etc. The second section comprised questions on breast-feeding knowledge, intention, and factors encouraging or discouraging breastfeeding mothers from the practice of exclusive breastfeeding. The third section comprised questions on problems of exclusive breastfeeding among teenage rural mothers. In the qualitative phase, additional insights into some of the responses elicited from the survey were sought through face-to-face structured interviews and a focus group discussion session. Generally, qualitative methods provide in-depth information such as participants' perceptions and experiences. Despite the emphasis on depth, qualitative studies are often limited in scope. The face-to-face interview with breastfeeding mothers was focused on breastfeeding experiences and network of supports, while the interviews with the nurses investigated their job experiences and available 
supports that could facilitate breastfeeding initiation and duration among breastfeeding mothers attending the hospital. Lastly, the focus group discussion with grandmothers was on grand-mothers' knowledge, experiences, and dispositions towards exclusive breastfeeding.

\section{Methods of data analysis}

The quantitative data were analyzed using the Statistical Package for Social Scientists (SPSS) version 21. Frequency and percentages were used to describe the demographic and socio-economic situation of the teenage rural mothers and the breastfeeding beliefs and practices of the women. The findings are presented as both discussions and tables. The in-depth interviews with nurses were conducted in English at the health facility, whilst the interviews with nursing mothers and the focus group discussion with grandmothers were conducted in the Yoruba language at preferred locations. All the in-depth interviews and focus group discussions were recorded through audiotape. The first author moderated all the sessions, while the second author acted as the notetaker. The interviews lasted for an average of 45 minutes, while the focus group discussion lasted for one hour thirty minutes. All the interviews were transcribed verbatim. The interviews that were conducted in Yoruba were transcribed and translated into English by an expert in both languages. Both texts were later given to another expert in linguistic to ensure proper and actual translation. Subsequently, the audiotaped interviews and the field notes were used to verify the transcribed texts, ensuring that they were correctly transcribed to preserve the meaning of the participants' words. All the transcribed and translated texts were coded. Coding took place in two stages: open and axial coding. These codes were recorded, based on the major themes of the study, to form categories. The contents in these categories were used to clarify and enhance the quantitative results

\section{Ethical consideration}

Institutional approval was received from the Federal College of Education Research and Ethics Committee. At all levels, participants were briefed on the study objectives and their consent was received either by filling the informed consent forms or by giving verbal approval before administering any of the research procedures. Besides, all the members (i.e respondents) were informed of the right to withdraw their participation in the study at any stage.

\section{Result and Discussion}

Socio-economic characteristics of the teenage rural mothers' in the study area.

Result in Table 1 reveals that above half (59.1\%) and $60.0 \%$ of the respondents were between the age of 17 - 19 years in Oyo and Ogun State respectively, 29.3\% and 27.0\% of them were between 20 - 22 years of age and few $(11.6 \%$ and $12.0 \%)$ of the respondents were less than 17 years of age in Oyo and Ogun State respectively. The mean age of the respondents was 18 years in both states. This result negates the finding of Somefun, et al., (2016) Ugboaja, et al., (2013) and Takai, et al., (2015). On marital status, the result showed that Half (51.6\% and $50.0 \%$ ) of the respondents in Oyo and Ogun State were married (i.e staying together with the husband under one roof) while $48.4 \%$ and $50.0 \%$ of the respondents in Oyo and Ogun were separated (i.e staying away from one another). This is an indication that about half of the respondents sampled were able to really stayed with their husband and nurture the baby together while others stay alone or stayed with their parent, aunt, neighbor, and so on. The majority $(67.4 \%$ and $72.5 \%)$ of the respondents were practicing Christianity, $27.9 \%$ and $22.5 \%$ of them practice Islam and a few $(4.7 \%$ and $5.0 \%)$ of them practice traditional religion in Ogun and Oyo State respectively. This implies that all three religions were being observed by the respondents sampled for this study. Most $(81.4 \%$ and $93.0 \%)$ of the respondents were Yoruba in both Oyo and Ogun State respectively, while a few $(8.4 \%$ and $3.0 \%, 7.4 \%$ and $2.0 \%, 2.8 \%$, and $2.0 \%)$ were Hausa, Igbo, and Igede by ethnicity. This implies the study area sampled accommodate many tribe and age range of teenage mothers spread across many ethnicities. The mean household size was 3 and 4 persons in Oyo and Ogun State respectively. The majority $(73.0 \%$ and $71.5 \%$ ) of the respondents in Oyo and Ogun State had formal education ranging from primary to tertiary education, while $27.0 \%$ and $28.5 \%$ of them in Oyo and Ogun State had no formal education. The highest percentage $(27.9 \%$ and $25.5 \%$ ) of the respondents in Oyo and Ogun State were farmers, while $19.1 \%$ and $22.5 \%$ were traders, $23.7 \%$ and $22.0 \%$ were artisan in the area sampled. However. $11.6 \%$ and $11.5 \%$ of the respondents in Oyo and Ogun State were unemployed. Result revealed that the highest percentage $(38.6 \%$ and $38.0 \%)$ of the respondents in Oyo and Ogun State had home delivery as their place of birth, while 29.3\% and 31.0\% had traditional birth attendant, $17.7 \%$ and $17.0 \%$ had private and $14.4 \%$ and $14.0 \%$ had public as their place of birth in the area sampled. 
Table 1: Distribution based on socio-economic characteristics of rural teenage mothers $(\mathrm{n}=\mathbf{2 1 5}$ and 200$)$.

\begin{tabular}{|c|c|c|c|c|}
\hline \multirow{2}{*}{ Variables } & \multicolumn{2}{|c|}{ Ogun state } & \multicolumn{2}{|c|}{ Oyo state } \\
\hline & Frequency & Percentage (\%) & Frequency & Percentages (\%) \\
\hline \multicolumn{5}{|l|}{ Age } \\
\hline Less than 17 & 25 & 11.6 & 24 & 12.0 \\
\hline $17-19$ & 127 & 59.1 & 122 & 61.0 \\
\hline $20-22$ & 63 & 29.3 & 54 & 27.0 \\
\hline Mean age & & 18.39 & & 18.25 \\
\hline \multicolumn{5}{|l|}{ Marital status } \\
\hline Married & 111 & 51.6 & 100 & 50.0 \\
\hline Separated & 104 & 48.4 & 100 & 50.0 \\
\hline \multicolumn{5}{|l|}{ Religion } \\
\hline Christianity & 145 & 67.4 & 145 & 72.5 \\
\hline Islam & 60 & 27.9 & 45 & 22.5 \\
\hline Traditional & 10 & 4.7 & 10 & 5.0 \\
\hline \multicolumn{5}{|l|}{ Ethnicity } \\
\hline Hausa & 18 & 8.4 & 6 & 3.0 \\
\hline Yoruba & 175 & 81.4 & 186 & 93.0 \\
\hline Igbo & 16 & 7.4 & 4 & 2.0 \\
\hline Igede & 6 & 2.8 & 4 & 2.0 \\
\hline \multicolumn{5}{|l|}{ Household size } \\
\hline Less than 4 & 59 & 27.4 & 54 & 27.0 \\
\hline $4-6$ & 91 & 42.3 & 105 & 52.5 \\
\hline $7-9$ & 65 & 30.2 & 41 & 20.5 \\
\hline \multicolumn{5}{|l|}{ Educational level } \\
\hline No formal education & 58 & 27.0 & 57 & 28.5 \\
\hline Primary education & 69 & 32.1 & 52 & 26.0 \\
\hline Secondary education & 46 & 21.4 & 47 & 23.5 \\
\hline Tertiary education & 42 & 19.5 & 44 & 22.0 \\
\hline \multicolumn{5}{|l|}{ Occupation } \\
\hline Farming & 60 & 27.9 & 51 & 25.5 \\
\hline Trading & 41 & 19.1 & 45 & 22.5 \\
\hline Civil servant & 38 & 17.7 & 37 & 18.5 \\
\hline Artisan & 51 & 23.7 & 44 & 22.0 \\
\hline Unemployed & 25 & 11.6 & 23 & 11.5 \\
\hline \multicolumn{5}{|l|}{ Place of delivery } \\
\hline Public hospital & 31 & 14.4 & 28 & 14.0 \\
\hline Private hospital & 38 & 17.7 & 34 & 17.0 \\
\hline Traditional birth & 63 & 29.3 & 62 & 31.0 \\
\hline Home delivery & 83 & 38.6 & 76 & 38.0 \\
\hline
\end{tabular}

Source: Field survey, 2018

Infant feeding pattern among teenage mothers in the study area.

Result in Table 2 revealed that a moderate level of awareness of breastfeeding $(60.9 \%$ and $62.0 \%)$ among the teenage rural mothers was recorded in the area sampled. This implies that respondents received information about the exclusive breastfeeding practices on a reasonable level to benefit them in their communities. Almost One-third (33.0\% and 32.0\%) of the respondents in Oyo and Ogun indicates that feeding of the baby start within the first 2 hours after birth, while $19.5 \%$ and $28.0 \%$ of the respondents feed the baby more than 2 hours of birth, $20.9 \%$ and $13.5 \%$ of them reveals that feeding of the baby start on the second day after birth, while $20.9 \%$ and $11.0 \%$ of the respondents in Ogun and Oyo States could not remember when they start to feed their baby in the study area. Above half $(51.6 \%$ and $55.5 \%)$ of the teenage rural mothers reveal that they practice exclusive breastfeeding, while $48.4 \%$ and $44.5 \%$ of the in Oyo and Ogun States did not practice exclusive breastfeeding in the study area. This implies that most of them still yield to the advice of the nurses after birth. This study also revealed that although the majority of women knew about the advantages of EBF and received good support from the hospital staff, only half of the women initiated and continued EBF until hospital discharge. On the adequacy of information about exclusive breastfeeding, the result revealed that above half $(56.3 \%$ and $61.0 \%)$ of the respondents in Oyo and Ogun State perceived good adequacy of information in the area sampled. It was gathered that the majority $(62.2 \%)$ of the respondents in Oyo State and almost half $(46.9 \%)$ of the respondents in Ogun State practiced exclusive breastfeeding for over 8 weeks, while $14.4 \%$ and $23.4 \%$ of the respondents in 
Oyo and Ogun States practiced exclusive breastfeeding for just $5-6$ weeks in the study area. Most (36.3\% and $37.5 \%$ ) of the respondents in Oyo and the Ogun States admitted that they breastfeed their child for more than 11 times daily in Ogun and Oyo State respectively, while 32.6\% and 32.0\% breastfeed their child for 9 - 11 times a day, $18.1 \%$ and $15.5 \%$ breastfeed for $6-8$ times and $13.0 \%$ and $15.0 \%$ breastfeed for up to 6 times daily. It was observed that $26.5 \%$ and $33.0 \%$ of the respondents in Oyo and Ogun State opined that they intend to breastfeed their babies for 13 - 18 months, while $26.5 \%$ and $32.0 \%$ of them intend to breastfeed for $7-12$ months, $18.6 \%$ and $20.5 \%$ of them intend to breastfeed their babies for 6 months and $13.0 \%$ and $3.0 \%$ of them intend to breastfeed their babies for $19-24$ months. These findings are consistent with the findings of other studies that it is not only maternal intention and attitude, but many other maternal demographic and individual variables associated with predicted breastfeeding duration (Bai et al., 2011; Sheehan et al., 2010; Scott et al., 2001; Lawton et al., 2012). Finding reveals that $43.7 \%$ and $42.0 \%$ of the respondents in Oyo and Ogun State respectively reveals that they did not know the length of times or take a count at all for each breastfeeding while $39.5 \%$ and $41.5 \%$ revealed half an hour for the length of times for each breastfeeding in the study area.

"From my own experiences, after retiring from the labour work, farm or workplace breastfeeding at night while asleep is much easier than while being awake doing something or attending to some task and it is still a common practice among us to date and we learn it through our mother as a common norm

(FGD with some teenage mothers in Ogun State)."

\begin{abstract}
"Breastfeeding baby while sleeping at night is a way of keeping babies asleep with little interruption. It also allows the baby to sleep comfortably, relax, and suck at easy whenever he/she wakes up without disturbing the mothers at all. (FGD with a Grandmother View)"

From experiences, after reticent from the farm, trading, or market, breastfeeding at night while asleep is the best and could be much easier than while awake; it is still common among breastfeeding mothers to date (FGD with grandmothers).

Furthermore, the grandmothers described breastfeeding practices while sleeping at night as a way of keeping or allowing the babies asleep with little disruption. This position was validated in the narratives of some teenage rural mothers: 'if the child refuses to sleep on time or at night, it is largely the responsibility of the mothers to pacify the baby. This often disrupts our sleep in most cases.'
\end{abstract}

Table 2: Breastfeeding Practices

\begin{tabular}{|l|l|l|}
\hline Variables & Oyo (\%) & Ogun (\%) \\
\hline When did you start to feed your baby & & \\
\hline Immediate after birth & $12(5.6)$ & $31(15.5)$ \\
\hline Within the first 2hrs after birth & $71(33.0)$ & $64(32.0)$ \\
\hline After more than 2hrs of birth & $42(19.5)$ & $56(28.0)$ \\
\hline On the second day after birth & $45(20.9)$ & $27(13.5)$ \\
\hline Cannot remember & $45(20.9)$ & $22(11.0)$ \\
\hline Receive information about exclusive breastfeeding & & \\
\hline Yes & $131(60.9)$ & $124(62.0)$ \\
\hline No & $84(39.1)$ & $76(38.0)$ \\
\hline Did you practice exclusive breastfeeding & & \\
\hline Yes & $111(51.6)$ & $111(55.5)$ \\
\hline No & $104(48.4)$ & $89(44.5)$ \\
\hline Perceived adequacy of the information & & \\
\hline Yes & $121(56.3)$ & $122(61.0)$ \\
\hline No & $94(43.7)$ & $78(39.0)$ \\
\hline For how long did you practice exclusive breastfeeding & & \\
\hline $1-2$ weeks & $3(2.7)$ & $2(1.8)$ \\
\hline $3-4$ weeks & $10(9.0)$ & $13(11.7)$ \\
\hline $5-6$ weeks & $16(14.4)$ & $26(23.4)$ \\
\hline $7-8$ weeks & $13(11.7)$ & $18(16.2)$ \\
\hline Above 8 weeks & $69(62.2)$ & $52(46.9)$ \\
\hline How often do you breastfeed your baby daily & & \\
\hline Less than 6 times & $28(13.0)$ & $30(15.0)$ \\
\hline $6-8$ times & $39(18.1)$ & $31(15.5)$ \\
\hline $9-11$ times & $70(32.6)$ & $64(32.0)$ \\
\hline Above 11times & $78(36.3)$ & $75(37.5)$ \\
\hline
\end{tabular}




\begin{tabular}{|l|l|l|}
\hline Variables & Oyo (\%) & Ogun (\%) \\
\hline Length of times for each breastfeeding & & \\
\hline Less than half-hour & $36(16.7)$ & $33(16.5)$ \\
\hline Half an hour & $85(39.5)$ & $83(41.5)$ \\
\hline I don't know & $94(43.7)$ & $84(42.0)$ \\
\hline What periods are you intend to breastfeed your baby & & \\
\hline Less than 6month & $33(15.3)$ & $23(11.5)$ \\
\hline 6 months & $40(18.6)$ & $41(20.5)$ \\
\hline $7-12$ months & $57(26.5)$ & $64(32.0)$ \\
\hline $13-18$ months & $57(26.5)$ & $66(33.0)$ \\
\hline $19-24$ months & $28(13.0)$ & $6(3.0)$ \\
\hline
\end{tabular}

Source: Field survey, 2018

Factors that can influence the adoption of exclusive breastfeeding practices in the study area.

With the level of breastfeeding awareness among the respondents sampled in Oyo and Ogun State, it was important to understand the factors that could help the teenage rural mothers in deciding to be involved in exclusive breastfeeding practices. The result in Table 3 showed that personal determination/experience was with the mean value of 3.73 and 3.78 in Oyo and Ogun State respectively. This implies that the majority of the respondents had a strong will and learn from people about the issue of breastfeeding with the understanding of the nutritional benefit attributed to breast milk. However, it was gathered that encouragement from their mothers was with the mean value of 3.72 and 3.76 in Oyo and Ogun State respectively. This is an indication that most grandmothers support adequate breastfeeding for a certain period. In the FGD, four of the grandmothers recounted how their involvement in breastfeeding had helped their daughter-in-law to initiate and continue breastfeeding, although not exclusively, but continued breastfeeding up to a year and beyond, while three of the grandmothers also support satisfactory breastfeeding practices which have help people over time, exclusive breastfeeding was practiced by my daughter-in-law to initiate and continue to practice. Furthermore, nurse and midwife advice was with the mean value of 3.70 and 3.55 in Oyo and Ogun State respectively. The health personnel instruction during ante-natal and postnatal help respondents to adopt the use of exclusive breastfeeding practices to some extent in the study area. A more probe on factor influencing the adoption of exclusive breastfeeding showed that social pressure on mothers was with a mean value of 3.67 and 3.64 , and encouragement from mother-in-law was with the mean value of 3.67 and 3.64 in Oyo and Ogun State respectively attracted similar value and proportions. Also, Encouragements from husbands were with the mean value of 3.59 and 3.64, and neighbours support and advice were with the mean value of 3.59 and 3.64 in Oyo and Ogun State Nigeria respectively attracted equal value. In the in-depth interviews with nurses, some of them described their involvement in regular health education and quality information on breastfeeding practices during antenatal and postnatal visits to the health facility. This form of education was described as an essential responsibility that should be undertaken at the household level.

Table 3: Factor influencing the adoption of exclusive breastfeeding practices.

\begin{tabular}{|l|c|c|c|c|}
\hline & \multicolumn{2}{|c|}{ Oyo (n= 215) } & \multicolumn{2}{c|}{ Ogun (n= 200) } \\
\hline Factor influencing & Mean & \multicolumn{1}{|c|}{ Std. dev } & \multicolumn{1}{l|}{ Mean } & Std. dev \\
\hline Encouragement from mothers & $\mathbf{3 . 7 2}$ & $\mathbf{1 . 1 4 8}$ & $\mathbf{3 . 7 6}$ & 1.179 \\
\hline Social pressure on mothers & 3.67 & 1.139 & 3.64 & 1.200 \\
\hline Personal determination/experience & $\mathbf{3 . 7 3}$ & $\mathbf{1 . 1 4 8}$ & $\mathbf{3 . 7 8}$ & $\mathbf{1 . 1 7 9}$ \\
\hline Husband encouragement at all time & 3.59 & 1.304 & 3.64 & 1.253 \\
\hline Nurse and midwife advice & 3.70 & 1.033 & 3.55 & 1.050 \\
\hline Encouragement from mother-in-law & 3.67 & 1.139 & 3.64 & 1.200 \\
\hline Media and publicity & 3.68 & 1.033 & 3.55 & 1.050 \\
\hline Neighbours support and advice & 3.59 & 1.304 & 3.64 & 1.253 \\
\hline Religious bodies role and encouragement & 2.95 & 1.149 & 3.70 & 1.148 \\
\hline Availability of a balanced diet & 2.78 & 1.116 & 3.42 & 1.241 \\
\hline
\end{tabular}

Source: Field survey, 2018

Problems encountered by teenage mothers in the practice of exclusive breastfeeding.

Results in Table 4 reveal that there are varying degrees according to the mean value of the problems encountered by teenage mothers in the practice of exclusive breastfeeding in the selected area in Oyo and Ogun State. Finding in Ogun based on the qualitative revealed that fear of infant becoming addicted to breast milk alone $(=2.52 \pm$ $0.736)$, the baby continued to be hungry after feeding times $(=2.29 \pm 0.835)$, mental health problems $(2.19 \pm$ $0.768)$, tiring of exclusive $(=1.94 \pm 0.639)$, nature of work/business issues $(=1.85 \pm 0.441)$, lack of breast milk to 
satisfy mu mind $(=1.78 \pm 0.698)$ and lack of husband support $(1.69 \pm 0.493)$ were common problems to exclusive breastfeeding among teenage mothers in Ogun State, while respondents in Oyo State reveal that lack of breast milk to satisfy my child $(=2.34 \pm 0.815)$, tiring of exclusive breastfeeding $(=2.23 \pm 0.628)$, due to pregnancy $(2.23 \pm 0.762)$, fear of infant becoming addicted to breast milk alone $(=2.18 \pm 0.826)$, nature of work/business issues $(=2.12 \pm 0.584)$ and the baby continued to be hungry after feeding times $(=2.06 \pm 0.708)$ were the common problems to exclusive breastfeeding among teenage mothers in Oyo State. A recurrent position in the interviews with breastfeeding teenage mothers and nurses was that the problems of exclusive breastfeeding might be against the desires of some teenage mothers in both Ogun and Oyo State. As described by one of the teenage mothers:

"I find it very difficult to breastfeed for 6 months. This is because I always experience/complain about breast aches/pain as their babies suck hard for the milk to flow. Nevertheless, a breastfeeding mother needed support and a well-nourished balanced meal that will experience constant secretion of milk to their babies. But when such support is lacking and the secretion of milk fluctuates with grievances of breast pain, infant supplement becomes an alternative for most of the teenage mothers"

\section{(Breastfeeding teenage mother, aged 21)}

"Some teenage rural mothers find it very difficult to breastfeed for 6months due to their breast aches as their babies had to suck hard for the milk to flow gradually. However, a breastfeeding mother with the support of the husband and consumes a well-nourished balanced meal, will experience constant secretion of breast milk to their baby. But when such support is lacking and the secretion of milk fluctuates with complaints of breast pain, infant supplement becomes an alternative"

(Breastfeeding mother, aged 20).

Four (4) among the grandmothers sampled argued that the introduction of semi-solids and water alongside breast milk would enable a child to grow faster and allow their mothers to resume economic activities without a prolonged break/delay. There are a series of variations in the exclusive breastfeeding in Ogun and Oyo State rate compared with others (Lawoyin, et al., 2001; Sobo, et al., 2008). The variations in the occurrence rates may be due to the sample size used and the research design adopted for the study. However, the low practice of exclusive breastfeeding among teenage rural mothers remains a great concern, especially with the high level of awareness as revealed in the initiation rate and perceived benefits associated with exclusive breastfeeding.

Table 4: Problems encountered by teenage mothers in the practice of exclusive breastfeeding in the study area.

\begin{tabular}{lll}
\hline Problems & $\begin{array}{l}\text { Ogun } \\
\pm \text { SD) }\end{array}$ & $\begin{array}{c}\text { (Mean } \\
\text { Oyo } \\
\pm \text { SD) }\end{array}$ \\
\hline The baby continued to be hungry after feeding a times & $2.29 \pm 0.835$ & $2.06 \pm 0.708$ \\
Maternal health problem & $2.19 \pm 0.768$ & $1.91 \pm 0.581$ \\
Fear of infant becoming addicted to breast milk alone & $2.52 \pm 0.736$ & $2.18 \pm 0.826$ \\
Pains in my breast & $1.26 \pm 0.578$ & $2.01 \pm 0.701$ \\
Mother in -law pressure to wean the baby & $1.14 \pm 0.342$ & $1.74 \pm 0.632$ \\
Lack of a husband's support & $1.69 \pm 0.493$ & $2.02 \pm 0.749$ \\
Nature of work/business issues & $1.85 \pm 0.441$ & $2.12 \pm 0.584$ \\
Tiring of exclusive breastfeeding & $1.94 \pm 0.639$ & $2.23 \pm 0.628$ \\
Lack of breast milk to satisfy my child & $1.78 \pm 0.698$ & $2.34 \pm 0.815$ \\
Baby refusal of breast milk & $1.47 \pm 0.548$ & $1.79 \pm 0.635$ \\
Losing weight & $1.32 \pm 0.526$ & $1.87 \pm 0.681$ \\
Feeling dizzy at times during exclusive breastfeeding & $1.44 \pm 0.555$ & $1.88 \pm 0.615$ \\
Due to pregnancy & $1.50 \pm 0.702$ & $2.23 \pm 0.762$ \\
\hline
\end{tabular}

\section{Source: Field survey, 2018}

Ho1: There is no significant difference between the problems encountered by teenage rural mothers in the practice of exclusive breastfeeding in the study area.

The T-test results in Table 5 show there is a significant difference $(t=93.732)$ in the problems encountered by teenage rural mothers in the practice of exclusive breastfeeding in the study area. This indicates that teenage rural mothers perceive the problems encountered in the practice of exclusive breastfeeding in the study area. Therefore, the hypothesis that stated there is no significant difference between the problems encountered by teenage rural mothers in the practices of exclusive breastfeeding in Ogun and Oyo State was rejected. 
Table 5: Test of means between the problems encountered by teenage rural mothers in the practice of exclusive breastfeeding in Ogun and Oyo State

\begin{tabular}{lllcllc}
\hline Area & Mean & Standard deviation & df & t-value & p-value & Decision \\
\hline Ogun State & 58.6500 & 6.51347 & 214 & 93.732 & 0.001 & $\mathrm{~S}$ \\
Oyo State & 60.5165 & 5.60425 & 199 & & & \\
\hline
\end{tabular}

Source: Field survey, 2018

Note: $\quad \mathrm{S}=$ Significant at 0.05 level, $\quad \mathrm{NS}=$ Not significant at 0.05 level.

\section{Conclusion and Recommendation}

Conclusion

Based on the findings of the result in the study area, breastfeeding teenage rural mothers are faced with multiple problems as they struggle to practice exclusive breastfeeding. Thus, scaling up of exclusive breastfeeding among teenage rural mothers in Oyo and Ogun States requires intensive efforts at the macro, meso, and micro levels of Nigerian society. Even though breastfeeding has found universal acceptability in the area sampled as evidenced by the fact that all the children were breastfed, the knowledge and practice of EBF are abysmally low among the teenage rural mothers in Oyo and Ogun States respectively. To achieve the goals of the MDG-4, there is the need to institute intervention measures aimed at increasing EBF rates in the study community.

\section{Recommendation}

To improve the practice of exclusive breastfeeding among the teenage rural mothers in study areas.

1. The Primary Health Care Development Board (PHCDB) in Oyo and Ogun States should strengthen the existing Primary Health Care (PHC) facilities through capacity building for healthcare personnel, the establishment of more facilities where necessary, and subsidizing products and services. Such facilities should be sited as close to the rural communities as possible with their active participation in the planning, implementation, and monitoring.

2. Also, exclusive breastfeeding should be incorporated into a comprehensive health education and promotion strategy to bridge the knowledge gap of most of the teenage rural mothers in the study area.

3. Policies aimed at improving exclusive breastfeeding uptake should also incorporate significant others (grandmothers, mothers in-laws, and husbands) in the process of encouraging breastfeeding mothers.

4. Health workers and authorities do not only target the mother as the sole recipient of infant feeding education, but also other caregivers including relatives, friends, the general community, and the public at large since anyone could be a reference point or a significant other for a lactating mother.

5. Also, infant feeding educators should take into consideration the culture and meanings of practices of the mothers they educate since cultural beliefs are very difficult to change.

\section{Acknowledgment}

The research team genuinely registers our deep appreciation to Tertiary Education Trust Fund (TETFUND) Abuja. The Provost Federal College of Education Osiele, Abeokuta, Ogun State Nigeria, Dr. A.A Ajayi, the management team, and the TETFUND Desk Officer, Mr. A. A. Abati for granting us the endorsement and release of funds to carry out this research work titled "Assessment of Exclusive Breastfeeding Practices among Teenage Rural Mothers in Selected Agrarian Community of Southwest Nigeria”. The authors also wish to acknowledge Primary Health Care (PHC) in the most agrarian community in Oyo and Ogun State for permitting us to meet the teenage rural mothers within their premises. Finally, we thank our respondents (teenage rural mothers), Nurses, and Grandmothers in both Oyo and Ogun states for their co-operation and support. We also wish to thank our anonymous reviewers for their very useful contribution, correction, and comments which helped to bring the paper to the present level.

Sponsored by:

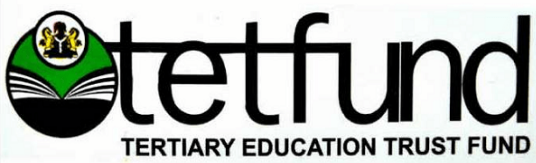

\section{References}

Ajibade, G. O (2004). The Role of Yoruba Traditional Birth Attendants in GlobalHealth Care Delivery. In Locating the Local in the Global: Voices on a Globalized Nigeria. Edited by: Akinrinade, S, Kolawole, M, Mojola, I, Ogungbile, D. A. New York, USA; 121-135.

Anyamele, O. D (2009). Urban and rural differences across countries in child mortality in Sub-Saharan Africa. J Health Care Poor Underserved. 20:90-98. 
Bai, Y.K., Wunderlich, S., and Fly, A. (2011). Predicting intentions to continue exclusive breastfeeding for 6 months: A comparison among racial/ethnic groups. Maternal \& Child Health Journal, 15(8), 1257-1264. DOI:10.1007/s10995-010.

Cameron, R A. (2009). sequential mixed model research design: Design, analytical, and display issues. Int J Soc Res Meth 3(2):140-152.

Cripe, E. T. (2008). Supporting breastfeeding? nursing mothers' resistance to and accommodation of medical and social discourses. Emerging Perspective in Health Communication: Meaning, Culture, and Power. Edited by: Zoller H. M, Dutta, M. J, New York: Routledge Taylor and Francis Group, 63-84.

Gartner, L. M, Morton, J, Lawrence, R. A, Naylor, A. J, O’Hare, D, Schanler, R. J, and Eidelman, A. I. (2005). American Academy of Pediatrics Section on Breastfeeding: Breastfeeding and the use of human milk. Pediatrics, 115:496-506.

Grassley J, and Eschiti, V. (2008). Grandmother breastfeeding support: What do mothers need and want? Birth. 35 (4): $329-335$.

Henry, B. A, Nicolau, A. I, Americo, C. F, Ximenes, L. O, Bernheim, R. G, and Oria, M. O. B. (2010). Sociocultural factors influencing breastfeeding practices among low-income women in Fortaleza-Ceara-Brazil: a Leininger's sunrise model perspective. Enfermeria Global [http://www.um.es/eglobal].

Ip, S, Chung, M, and Raman, G. (2007). "Breastfeeding and maternal and infant health outcomes in developed countries". Evidence Report/Technology Assessment; 153: 1-186.

Jennifer, F., Elaine, B., Athena, S., and Virginia, S. (2013). We only talk about breastfeeding: A discourse analysis of infant feeding messages in antenatal group-based education. Midwifery, 29(5), 425-433.

Jones G, Steketle, R. W, Black, R. E, Bhutta, Z. A, and Morris, S. S, (2003). Bellagio child survival strategy group. How many child deaths can we prevent this year? Lancet. 362: $65-71$.

Joshi, P.C, Angdembe, M.R, Dae, S.K, Ahmed, S, Faruque, A.R, and Ahmed T. (2014). Prevalence of exclusive breastfeeding and associated factors among mothers in rural Bangladesh: a cross-sectional study. Int Breastfeed J. 9: 7.

Kramer, M. S, and Kakuma, R. (2004). Optimal duration of exclusive breastfeeding (Cochrane Review). Cochrane Database Syst Rev; 8:CD00123517.

Kramer, M. S. (2010). "Breast is best": the evidence. Early Hum Dev. 2010;86(11):729-732. DOI: 10.1016/j.earlhumdev.08.005.

Lawoyin, T. O., Olawuyi, J. F., and Onadeko, M. O. (2001). Factors associated with exclusive breastfeeding in Ibadan, Nigeria. J Hum Lact 2001, 17(4):321-325.

León-Cava, N., Lutter, C., Ross, J., and Martin, L. (2002). Quantifying the Benefits of Breastfeeding: A Summary of the Evidence. Washington, USA: The Food and Nutrition Program (HPN), Pan American Health Organization (PAHO), The Linkages Project.

Li, R., Fein, S., Chen, J., and Grummer-Strawn, L. (2008). Why mothers stop breastfeeding: mothers' selfreported reasons for stopping during the first year. Pediatrics, 122, S69-S76.

Malla, D. S, Giri, K. Karki, C., and Chaudhary, P. (2011). Achieving millennium development goals 4 and 5 in Nepal. BJOG. 118:60-68.

Moore, E. R., and Coty, M. (2006). Prenatal and postpartum focus groups with primiparas: Breastfeeding attitudes, support, barriers, self-efficacy, and intention. Journal of Pediatric Health Care: Official Publication of National Association of Pediatric Nurse Associates \& Practitioners, 20(1), 35-46.

Murimi, M., Dodge, C. M., Pope, J., and Erickson, D. (2010). Factors that influence breastfeeding decisions among special supplemental nutrition program for women, infants, and children participants from Central Louisiana. Journal of the American Dietetic Association, 110(4), 624-627. DOI:10.1016/j.jada. 2009.12.019.

National Population Commission (NPC) and ICF Macro (2009). National Demographic and Health Survey 2008 Calverton, Maryland, USA: NPC and ICF Macro;

National Population Commission (Nigeria) and ICF International. Nigeria Demographic and Health Survey 2013. Rockville, Maryland, USA. National Population Commission and ICF International. 2014.

Nyanga, N. M, Musda, C, Otieno, A, and Kaseje, D. (2012). Factors influencing knowledge and practice of exclusive breastfeeding in Nyando district, Kenya. African Journal of Food, Agriculture, Nutrition, and Development. 12(6).

Ogbuanu, C., Glover, S., Probst, J., Liu, J., and Hussey, J. (2011). The effect of maternity leave length and time of return to work on breastfeeding. Pediatrics [serial online], 127(6), e1414-e1427.

Ogunlesi, T. A. (2010). Maternal sociodemographic factors influencing the initiation and exclusivity of breastfeeding in a Nigerian semi-urban setting. Maternal Child Health J,14(3):459-465.

Ojofeitimi E.O, Esimai, O.A, Owolabi, O.O, Oluwabusi, O.O.F, and Olanuga, T.O. (2000). Breastfeeding practices in urban and rural health centers: impact of baby-friendly hospital initiative in Ile Ife, Nigeria. Nutr Health, 14:119-125.

Otoo, G. E., Anna, A. L., and Rafael, P. (2009). "Perceived incentives and barriers to exclusive breastfeeding 
among peri-urban Ghanaian women." Journal of Human Lactation, Vol. 25, No. 1, pp. 34-41.

Salami, K. K (2008). Household Social Reproductive Roles and Production of Child Health in Igbo-Ora, Southwestern Nigeria. Ph.D. thesis University of Ibadan, Sociology Department.

Scott, J., Landers, M., Hughes, R., and Binns, C. (2001). Factors associated with breastfeeding at discharge and duration of breastfeeding. Journal of Pediatrics and Child Health, 37(3), 254-261.

Sobo, R. A, Sokoya, G. O, Awonusi, P. A, and Odufuwa, B. A: (2008). Knowledge attitudes and practice of exclusive breastfeeding among rural mothers in Ijebu-Ode, Ogun State, Nigeria. W Afr J Nurs 2008, 19(2):121-124.

Somefun, O. D, and Latifat, I. (2016). "Determinants of postnatal care non-utilization among women in Nigeria." BMC Research Notes, Vol. 9, FINANo. 1, 2016, p. 21.

Takai, I. U. et al. (2015). "Factors responsible for under-utilization of postnatal care services in Maiduguri, north-eastern Nigeria." Sahel Medical Journal, Vol. 18, No. 3, 2015, p. 109.

Tella, A., Falaye, A, Aremu, O., and Tella A. A. (2008). Hospital-based assessment of breastfeeding behavior and practices among nursing mothers in Nigeria and Ghana. Pak J Nutr, 7(1):165-171.

Ugboaja, J. O., et al. (2013). "Barriers to postnatal care and exclusive breastfeeding among urban women in southeastern Nigeria." Nigerian Medical Journal: Journal of the Nigeria Medical Association, Vol. 54, No. 1, p. 45.

Ukaegbu, A. U, Ukaegbu, P. O, Onyeonoro, U. U, and Ubajaka, C. F. (2011). Determinants of breastfeeding among mothers in Anambra State, Nigeria. South Afr J Child Health. 5(4): $112-116$.

Wiener, R. C., and Wiener, M. A. (2011). Breastfeeding prevalence and distribution in the USA and Appalachia by rural and urban settings. Rural \& Remote Health, 11(2), 1-9.

World Health Organisation (2005), WHO Progress Report, 2005-2006.

World Health Organization (2007). Part I. Definitions. Indicators for defining infant and young child feeding practices: Conclusions of a consensus meeting held 6-8 November 2007 in Washington DC, USA. Available at http://whqlibdoc.who.int/publications/2008/9789241596664 eng.pdf.

World Health Organization (2009). Infant and young child feeding (IYCF) model chapter for textbooks for medical students and allied health professionals. Switzerland: World Health Organization; 2009.

World Health Organization (2010). the state of breastfeeding in 33 countries. 2010. Available at: http://www.worldbreastfeedingtrends.org.

World Health Organization. (2014). 10 facts about breastfeeding. Retrieved from http://www.who.int/features/factfiles/breastfeeding/en/. 